\title{
PENGELOLAAN SAMPAH BERBASIS PELIBATAN MASYARAKAT DI KELURAHAN MENTENG KECAMATAN JEKAN RAYA KOTA PALANGKA RAYA PROVINSI KALIMANTAN TENGAH
}

\section{Community Engagement-Based Waste Management in Menteng Subdistrict Jekan Raya Palangka Raya City, Central Kalimantan Province}

\section{Siska Dina Mariana}

Rita Rahmaniati

Universitas Muhammadiyah Palangkaraya, Palangka Raya, Central Kalimantan, Indonesia

Email :

siskadnmariana@gmail.com rahmaniatirita@gmail.com

Kata Kunci:

Pengelolaan

Sampah

Masyarakat

Keywords:

Management

Waster

Community

\section{Accepted}

Januari 2021

Published

April 2021

\begin{abstract}
Abstrak
Penelitian ini bertujuan untuk memberikan gambaran tentang pengelolaan sampah berbasis pelibatan masyarakat di Kelurahan Menteng Kecamatan Jekan Raya Kota Palangka Raya Provinsi Kalimantan Tengah.

Jenis penelitian yang digunakan adalah metode penelitian kualitatif. Sumber data dalam penelitian ini terdiri dari data primer dan data sekunder. Yang menjadi data primer adalah Kepala Seksi Pengelolaan Sampah di Dinas Perumahan Rakyat dan Kawasan Permukiman Kota Palangkaraya, UPT. Pengelolaan Sampah Terpadu Kecamatan Jekan Raya Wilayah II, Masyarakat di Kelurahan Menteng Kecamatan Jekan Raya Kota Palangkaraya, sedangkan sumber data sekundernya adalah Peraturan Daerah Kota Palangkaraya Nomor I Tahun 2017 Tentang Pengelolaan Sampah dan Kebersihan.

Berdasarkan hasil penelitian dapat dijelaskan bahwa Pengelolaan Sampah Berbasis Pelibatan Masyarakat di Kelurahan Menteng Kecamatan Jekan Raya Kota Palangka Raya Provinsi Kalimantan Tengah, secara umum belum maksimal hal ini karena (I) Tidak maksimalnya pelaksanaan sosialisasi (spanduk/banner) masyarakat masih belum patuh mengikuti Peraturan Daerah Nomor I Tahun 2017 (2) Pembinaan dan pengawasan masih kurang hanya dilakukan pada awalawal Peraturan Daerah di berlakukan (3) Peran Masyarakat dan swasta masih perlu ditingkatkan untuk mengoptimalkan pengelolaan sampah di Kelurahan Menteng Kecamatan Jekan Raya Kota Palangka Raya.
\end{abstract}

\section{Abstract}

This study aims to provide an effort to provide an overview of how waste management is based on community involvement in Menteng Village, Jekan Raya District, Palangka Raya City, Central Kalimantan Province.

The type of research used is qualitative research methods. Sources of data in this study consisted of primary data and secondary data. The primary data is the Solid Waste Management Section at the Palangkaraya City Residential and Settlement Service, UPT. Integrated Waste Management of Jekan Raya Region II District, Community in Menteng Village, Jekan Raya District, Palangkaraya City. While the secondary data source is Palangkaraya City Regional Regulation Number I of 2017 concerning Waste Management and Cleanliness.

Based on the results of the research, it can be explained that Waste Management Based on Community Involvement in Menteng Village, Jekan Raya District, Palangka Raya City, Central Kalimantan Province, in general this has not been maximized because (I) the implementation of socialization (banner / banner) is not maximal. Number I of 2017 (2) Guidance and supervision were still lacking, only at the beginning of the Regional Regulation (3) The role of the public and private sector still needs to be improved to optimize waste management in Menteng Village, Jekan Raya District, Palangka Raya City. 


\section{PENDAHULUAN}

Kota Palangka Raya merupakan Ibu Kota dari Kalimantan Tengah dengan pertambahan penduduk yang meningkat setiap tahun. Pertambahan penduduk dapat dilihat dari data Badan pusat Statistik Kota Palangkaraya, pada tahun 2017 : 275.667 ribu penduduk dan tahun 2018 : 283.612 ribu penduduk. Arus urbanisasi dan bertambahnya jumlah penduduk merupakan salah satu penyebab bertambahnya jumlah sampah yang dihasilkan. Sampah diartikan sebagai material sisa yang tidak di inginkan setelah berakhirnya suatu proses yang cenderung merusak lingkungan disekitarnya. Sampah dapat membawa dampak yang buruk pada kebersihan dan kesehatan manusia bila sampah dibuang secara sembarangan atau di tumpuk tanpa ada pengelolaan yang baik maka akan menimbulkan berbagai masalah kebersihan dan kesehatan pada masyarakat, karena tumpukan sampah yang dibiarkan tanpa dikelola dengan baik maka akan menimbulkan berbagai macam penyakit. Perubahan pola konsumsi masyarakat semakin beragam pula sampah yang dihasilkan. Akibatnya, untuk mengatasi sampah diperlukan biaya yang tidak sedikit dan lahan.

Pengelolaan sampah dimaksudkan agar sampah tidak membahayakan kesehatan manusia dan tidak mencemari lingkungan. Pengelolaan sampah juga dilakukan untuk memperoleh manfaat bagi kesejahteraan masyarakat. Hal ini didasari oleh pandangan sebagian warga masyarakat bahwa sampah merupakan sumber daya yang masih bisa dimanfaatkan dan bahkan memiliki nilai ekonomi. Pandangan tersebut muncul seiring dengan semakin langkanya sumber daya alam dan semakin rusaknya lingkungan.

Pemberlakuan perda tentang sampah kepada masyarakat Kota Palangka Raya yang membuang sampah sembarangan akan dikenakan sanksi pidana. Dimana masyarakat Kota Palangkaraya hanya bisa membuang sampah di TPS (Tempat Pembuangan Sampah) jam buang sampah di antaranya pukul 04:00 WIB - 07:00 WIB dan juga dilarang membuang Limbah Bahan Beracun dan Berbahaya (B3) serta sisa tebangan pohon harus dibuang di TPA (Tempat Pembuangan Akhir) dan tidak boleh di TPS atau Depo. Dilarang pula membakar sampah, baik dipekarangan, TPS maupun Depo Sampah. Dilarang membuang sampah di luar bak TPS, ataupun membongkar sampah di TPS. Selain itu, dilarang membuang sampah di drainase dan selokan.

Bagi warga yang kedapatan membuang sampah diluar jam yang telah ditetapkan maka akan diganjar hukum pidana serta dikenakan denda maksimal Rp.l.000.000 minimal Rp.50.000, tergantung dari pelanggaran sesuai dengan keputusan hakim. Namun dalam penerapannya masih ada masyarakat yang berani membuang sampah sebelum jam yang telah ditentukan, alasannya karena rumah dengan lokasi TPS sangatlah dekat sehingga tidak merasa takut saat mau membuang sampah kapanpun, walaupun sebelum jam 4:00 WIB-7:00 WIB. Sehingga tidak perlu merasa khawatir atau takut akan dirazia oleh petugas, (Wawancara dengan lbu Nomi sebagai penjual sayur di pasar mini/pasar datah manuah Kota Palangkaraya pada tanggal 29 April 
2020). Hal ini terjadi karena minimnya petugas pemantau dari dinas terkait.

Kesadaran masyarakat membuang sampah sesuai jam yang ditetapkan dalam penerapan Peraturan Daerah Nomor I Tahun 2017 tentang Pengelolaan Sampah dan Kebersihan (selanjutnya disebut dengan Perda Nomor I Tahun 2017) masih sangat kurang. Berdasarkan hasil observasi awal di Tempat Pembuangan Sampah (TPS) di Kecamatan Jekan Raya tepatnya Kelurahan Menteng nampak masih banyak sampah pada jam yang seharusnya sudaha bersih lokasi TPS. Hal ini mengindikasikan bahwa sebagian masyarat masih belum menerapkan peratuturan daerah tentang waktu pembungan sampah. Selain itu, tidak nampak petugas dari dinas terkait melakukan pengawasan, sehingga pelanggaran terus dilakukan oleh masyarakt dalam waktu membuang sampah. Berdasarkan wawancara awal dengan masyakat yang membuang sampah tidak pada waktunya, sebagian besar menjawab tidak tahu jadwal pembungan sampah dan belum mengetahui tentang Perda waktu pembungan sampah. Berdasarkan uraian di atas maka peneliti tertarik untuk melakukan penelitian mengenai Pengelolaan Sampah Berbasis Pelibatan Masyarakat di Kelurahan Menteng Kecamatan Jekan Raya Kota Palangka Raya Provinsi Kalimantan Tengah.

\section{METODOLOGI}

Penelitian ini menggunakan jenis penelitian kualitatif dengan menggunakan metode deskriptif. Informan dalam penelitian ini adalah UPT. Pengelolaan Sampah Terpadu Kecamatan Jekan Raya Wilayah II, Seksi Pengelolaan Sampah Dinas Perumahan Rakyat dan Kawasan
Permukiman Kota Palangka Raya, Masyarakat di Kelurahan Menteng Kecamatan Jekan Raya Kota Palangka Raya. Teknik pengumpulan data penelitian ini adalah observasi, wawancara dan dokumentasi. Instrumen penelitian yang digunakan adalah peneliti sendiri, serta perangkat penunjang seperti pedoman wawancara (interview guide). Teknik analisis data yang digunakan adalah reduksi data, penyajian data, dan verifikasi.

\section{HASIL DAN PEMBAHASAN}

\section{A. Jenis dan Volume Indikasi Sampah di Kelurahan Menteng}

Berdasarkan hasil pengamatan dan wawancara oleh peneliti kepada berbagai informan yaitu Kepala Seksi Pengelolaan Sampah Dinas Perumahan Rakyat dan Kawasan Permukiman Kota Palangka Raya, Kepala UPT. Pengelolaan Sampah Terpadu Kecamatan Jekan Raya Wilayah II, Pengelola Sampah, dan Masyarakat yang ada di Kelurahan Menteng Kecamatan Jekan Raya terkait Pengelolaan Sampah Berbasis Pelibatan Masyarakat di Kelurahan Menteng Kecamatan Jekan Raya Kota Palangka Raya Provinsi Kalimantan Tengah pada saat ini belum maksimal atau belum terlaksana dengan baik. Hal ini dapat dilihat dari hasil wawancara dari berbagai informan yang dianggap dapat memberikan pernyataan yang relevan. Di lapangan juga terlihat masih ada TPS yang penuh pada saat siang hari bahkan sampah dibuang ke selokan. Kurangnya sosialisasi dan pengawasan dari dinas terkait membuat masyarakat semakin menyepelekan peraturan daerah tersebut. Peneliti juga menemukan di lapangan bahwa petugas pengawas hampir tidak pernah terlihat lagi. 


\section{B. Peran Masyarakat Dalam Pengelolaan Sampah}

Peran masyarakat selama ini dalam pengelolaan sampah sangat dibutuhkan untuk menerapkan peraturan pemerintah Nomor I Tahun 2017. Dari hasil wawancara diketahui bahwa kebiasaan masyarat yang tidak sesuai dengan peraturan disebabkan karena ketidaktahuan adanya peraturan. Perlu keaktifan dari Dinas Perumahan Rakyat dan Kawasan Permukiman Kota Palangka Raya dalam hal pengawasan dilapangan. Selain itu perlu sekali sosialisasi lebih intensif menggunakan cara-cara yang lebih inovatif, sehingga mudah diterima dan dimengerti oleh masyarat.

\section{Sarana dan Prasarana Pengelolaan}

\section{Sampah di Kelurahan Menteng}

Adapun Sarana dan Prasarana Pengelolaan Sampah di Kelurahan Menteng adalah sebagai berikut:

Tabel I.

Daftar Sarana Prasarana di UPT-PST Jekan Raya II

\begin{tabular}{|c|l|c|c|}
\hline No & \multicolumn{1}{|c|}{ Nama Sarana } & Satuan & Keterangan \\
\hline I & $\begin{array}{l}\text { Kantor UPT. PST Jekan } \\
\text { Raya wilayah 2 }\end{array}$ & I Unit & Aset Pemkot \\
\hline 2 & $\begin{array}{l}\text { Depo Sampah Jalan G. } \\
\text { Obos XII }\end{array}$ & I Unit & Aset Pemkot \\
\hline 3 & $\begin{array}{l}\text { Kendaraan Roda Tiga } \\
\text { Angkutan Sampah }\end{array}$ & 23 Unit & Aset Pemkot \\
\hline 4 & Laptop & I Unit & Aset Pemkot \\
\hline 5 & $\begin{array}{l}\text { Printer } \\
6\end{array}$ & $\begin{array}{l}\text { I Unit } \\
\text { Meja Kerja }\end{array}$ & $\begin{array}{l}\text { Aset Pemkot } \\
\text { Aset Pemkot }\end{array}$ \\
\hline
\end{tabular}

Sumber data : Dinas Perumahan Rakyat dan Kawasan Permukiman Kota Palangka Raya

Tabel 2.

Kondisi Pegawai UPT.PST Jekan Raya II

\begin{tabular}{|c|l|c|c|c|}
\hline No. & \multicolumn{1}{|c|}{$\begin{array}{c}\text { Tingkat } \\
\text { Pendidikan }\end{array}$} & PNS & Honor & Jumlah \\
\hline 1. & SD & - & - & - \\
\hline 2. & SLTP & 1 & - & 1 \\
\hline 3. & SLTA & 5 & 7 & 12 \\
\hline 4. & Diploma III (D-III) & - & - & - \\
\hline
\end{tabular}

\begin{tabular}{|l|l|c|c|c|}
\hline 5. & Strata 1(S-1) & 1 & 2 & 3 \\
\hline 6. & Strata 2(S-2) & - & - & - \\
\hline \multicolumn{3}{|c|}{ Jumlah } & 16 \\
\hline
\end{tabular}

Sumber data : Dinas Perumahan Rakyat dan Kawasan Permukiman Kota Palangka Raya Tahun 2018

\section{Pengelolaan Sampah Berbasis Pelibatan}

\section{Masyarakat di Kelurahan Menteng}

Dari hasil wawancara kepada masyarakat di Kelurahan Menteng Kecematan Jekan Raya Kota Palangka Raya, masyarakat mengatakan bahwa mereka masih ada yang belum mengetahui adanya Peraturan Daerah yang mengatur tentang Jam Pembuangan Sampah. Sebagian masyarakat ada yang mengetahui Peraturan Daerah tersebut setengah-setengah, hanya mengetahui sebatas mengenai adanya denda yang akan diberikan oleh pemerintah jika membuang sampah lewat dari jam yang telah disebutkan di Peraturan Daerah Nomor I Tahun 2017 sedangkan untuk isi peraturan daerah tersebut tidak hanya membahas masalah denda, tetapi juga terkait dengan hal pemilahan sampah dan jenis sampai yang hanya boleh di TPS dan yang tidak boleh dibuang di TPS atau DEPO seperti jenis limbah bahan beracun dan berbahaya (B3), sisa tebangan pohon harus dibuang di TPA (tempat pembuangan akhir), adanya larangan membuang sampah diluar bak TPS ataupun membongkar sampah di TPS, dan larangan membuang sampah di drainase dan selokan masyarakat banyak yang tidak mengetahuinya.

Faktor-faktor yang mempengaruhi kurang maksimalnya pengelolaan sampah menurut Perda diantaranya kurangnya sosialisasi dari dinas terkait kepada masyakarat terlihat dari minimnya spanduk pemberitahuan tentang Peraturan 
Daerah Nomor I Tahun 2017 dimana hanya menemukan I spanduk saja yang tergantung didepan TPS daerah pasar mini atau Pasar Datah Manuah padahal lokasi TPS tersebut berjarak dekat kurang lebih 300 meter dengan Kantor UPT, kurangnya pengawasan sehingga kurang maksimalnya pengelolaan sampah terpadu Kelurahan Menteng Kecematan Jekan Raya. Selin itu, rendahnya partisipasi masyarakat, keadaan lingkungan dan sikap peduli terhadap lingkungan turut mempengaruhi pengelolaan sampah di Keluarahan Menteng. Hal ini senada dengan lapran penelitian Fitriza dkk. 2017 bahwa berdasarkan hasil analisis chi-square karakteristik masyarakat dan lingkungan pemukiman berhubungan positif sangat nyata dengan tingkat partisipasi masyarakat dalam pengelolaan sampah pemukiman di kecamatan Tungkal Ilir Kabupaten tanjung Jabung barat.

Dari sisi lain, dalam pelaksanaan pengelolaan sampah disampaikan disampaikan oleh Dinas Perumahan Rakyat dan Kawasan Permukiman Kota Palangka Raya khususnya UPT kendala-kendala yang dialami Pengelolaan sampah terpadu Kelurahan Menteng Kecamatan Jekan Raya adalah kurangnya jumlah petugas dan kurangnya koordinasi antara pimpinan ke bawah untuk menyusun jadwal pengawasan waktu membuang sampah, jenis sampah yang dibuang, membuang sampah di drainase dll. Pengelolaan sampah dengan pelibatan masyarakat akan sangat membantu pengeloaan sampah di Keluarahan Menteng lebih maksimal. Dapat dilakukan melalui pemberian reward atau memberikan punishment jika terbukti melakukan pelanggaran, sehingga untuk menjalankan peraturan daerah tersebut lebih maksimal.

\section{KESIMPULAN}

Berdasarkan hasil penelitian dapat dijelaskan bahwa Pengelolaan Sampah Berbasis Pelibatan Masyarakat di Kelurahan Menteng Kecamatan Jekan Raya Kota Palangka Raya Provinsi Kalimantan Tengah, secara umum belum maksimal hal ini karena (I) Tidak maksimalnya pelaksanaan sosialisasi (spanduk/banner) masyarakat masih belum patuh mengikuti Peraturan Daerah Nomor I Tahun 2017 (2) Pembinaan dan pengawasan masih kurang hanya dilakukan pada awal-awal Peraturan Daerah di berlakukan (3) Peran Masyarakat dan swasta masih perlu ditingkatkan untuk mengoptimalkan pengelolaan sampah di Kelurahan Menteng Kecamatan Jekan Raya Kota Palangka Raya.

\section{SARAN}

Berdasarkan kesimpulan diatas, maka diharapkan kepada Pemerintah Kota Palangka Raya agar dapat melaksanakan:

I. Mengupayakan optimalisasi penegakkan aturan daerah guna memaksimalkan pengelolaan sampah di Kelurahan Menteng Kecamatan Jekan Raya Kota Palangka Raya.

2. Untuk jam pembuang sampah kalau bisa ditambah misalnya dari jam 03:00 WIB- 06:00 WIB saja karena jam 07:00 WIB sudah jam kerja dan aktifitas masyarakat pasti sudah padat, dan paling tidak ada petugas pengawas di TPS untuk menjelaskan mengenai jam buang sampah agar masyarakat tidak bingung jam berapa wajib buang sampah. Dan 
tambahkan TPS (Tempat Pembuangan Sampah) di setiap permukiman yang padat penduduk.

3. Memaksimalkan pelaksanaan sosialisasi dengan memanfaatkan media cetak seperti spanduk/ banner serta rutin melakukan kunjungan ke setiap Kelurahan atau Kecamatan untuk memberikan pembinaan dan bimbingan secara khusus dan rutin untuk meningkatkan kesadarakan masyarakat betapa pentingnya menjaga lingkungan.

\section{REFERENSI}

Adisasmita, Rahardjo. 20II. Manajemen Pemerintah Daerah. Yogyakarta: Penerbit Graha Ilmu.

Anggara, Sahya. 2014. Kebijakan Publik. Bandung: CV. Pustakan Setia.

Badan Pusat Statistik, https://Palangkakota. bps.go. id, diakses jam 10.35 pada tanggal II September 2019.

Barsriyanta. 2007. Memanen Sampah. Yogyakarta: Kanisius.

Fitriza dkk. 2017. Partisipasi Masyarakat Dalam Pengelolaan Sampah Pemukiman Pada kecamatan Tungkil Ilir Kabupaten Tanjung Jabung barat. Jurnal IImu Pendidikan. Volume 15 Issue 2 (2017); 96-III

Gunawan, Imam. 2014. Metode Penelitian Kualitatif: Teori dan Praktik. Jakarta: PT Bumi Aksara. Edisi satu. Cetakan Kedua.

Nugroho, Riant. 2003. Good Governance. Bandung: Mandar Maju.

Pasolong,harbani. (20/3). Teori Administrasi Publik. Bandung: CV.Alfabeta.

Peraturan Daerah Kota Palangka Raya Nomor I Tahun 2017 Tentang Pengelolaan Sampah dan Kebersihan.

Peraturan Menteri Pekerjaan Umum Nomor 21 Tahun 2006 Tentang Kebijkan dan Strategi Nasional Pengembangan Sistem Pengelolaan Persampahan.

Peraturan Walikota Palangka Raya Nomor 43 Tahun 2017 Tentang Peraturan Pelaksanaan Peraturan Daerah Kota Palangka Raya Nomor I Tahun 2017 Tentang Pengelolaan Sampah dan Kebersihan.
Sugiyono, 2017. Metode Penelitian Kuantitatif, Kualitatif, R\&D. Bandung: Alfabeta. Cetakan Ke-25

Tahir Arifin. (20|4). Kebijakan Publik \& Transparansi Penyelenggaraan Pemerintah Daerah. Bandung : Alfabeta.

Undang-Undang Nomor 18 Tahun 2008 Tentang Pengelolaan Sampah. 